\title{
Mise en abyme e culturalismo: a novelística de Nuno Júdice
}

Miguel Real

CLEPUL - Centro de Literaturas e Culturas Europeias e Lusófonas da Faculdade de Letras de Lisboa

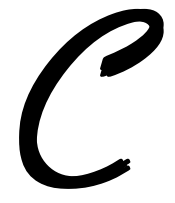

om excepção de O Tesouro da Rainha do Sabá (1984), ${ }^{1}$ "conto pós-moderno" (segundo o autor), cruzamento estilístico de Romantismo e Naturalismo envolvido por uma inspiração "fantástica", todas as narrativas de Nuno Júdice, indubitavelmente o melhor novelista português vivo, são subordinadas à dificílima técnica estilística de mise en abyme. É, aliás, o único ficcionista português vivo que utiliza abundantemente esta técnica, trabalhada pelos restantes apenas em uma ou outra narrativa. Ainda jovem, não dominando totalmente esta técnica, já Nuno Júdice dela se aproximava, como em Plâncton, novela obediente ao estilo fragmentário e desconstrucionista da década de 70, quando explora a comunidade de dimensões vivenciais das três personagens femininas (Rita, Rosa e Laura) ou quando o narrador explora a ideia nascida da "sobreposição de duas imagens". ${ }^{2}$ Mise en abyme explicita a técnica de narração que explora "em profundidade" ("abyme") uma particular representação da realidade (um elemento da narrativa) na qual se sobrepõe, em imagens vertiginosamente cruzadas, a totalidade (ou quase) da história narrada. Neste

${ }^{1}$ JÚDICE, 1984.

2 JÚDICE, 1981, p. 57. 
caso, por via da sobreposição de "duas imagens", Nuno Júdice explora "abissalmente", girando em círculos "concêntricos" e "excêntricos", ${ }^{3}$ os elementos da intriga ao ponto de provocar no leitor a sensação de uma irrealidade intemporal ou metahistórica, ausente de cronologia e geografia específicas. No conto pós-moderno de 1984, ainda não beijado por esta técnica, Nuno Júdice, porém, não deixa de a experimentar: "Durante a manhã, andei entre a coluna da Place de Vendôme e o obelisco da Concorde até que as duas imagens se sobrepusessem no meu espírito". ${ }^{4}$

Assim, como se evidenciou pelas duas citações, é por via do recurso a imagens diferentes sobrepostas no pensamento do narrador que o processo estilístico de mise en abyme se desencadeia em Nuno Júdice. Terá sido, porventura, no conto A Mulher Escarlate (1997) que Nuno Júdice assumiu para si esta técnica como modo de desenhar e narrar uma história, recusando conscientemente tanto o império da cronologia quanto a soberania da espacialidade, jogando ludicamente com as diversas personagens (Fernando Pessoa, Álvaro de Campos, o mago Aleister Crowley, a mulher escarlate...) num vórtice narrativo, forçando a mente do leitor a projectar-se num "abismo" interpretativo para o qual não encontra saída lógica: tempos e espaços misturam-se ("sobrepõem-se") numa espiral hermenêutica condutora a uma nova e superior realidade - a realidade estética do texto, própria da ficção, desapossada das categorias temporais e espaciais da realidade referencial.

Por via da leitura de velhos livros sobre as vidas e as lendas dos santos, o narrador de Por todos os Séculos (Quetzal, 1999), investiga alguns processos de santidade e de violação

${ }^{3}$ JÚDICE, 2009.

${ }^{4}$ JÚDICE, 1984, p. 22. 
sexual. De novo, o narrador sobrepõe a vivência da actualidade (processo jornalístico sobre a relação entre o presidente americano Clinton e a sua secretária Mónica) a tempos passados (a violação de Brísida Vaz pelo falso monge Estêvão Peres).

Em O Anjo da Tempestade (2004, prémio Fernando Namora), novela do autor que se aproxima mais de um romance e, entre todos, o seu melhor texto em prosa, Nuno Júdice funde o classicismo narrativo da escrita e o experimentalismo próprio da técnica de mise en abyme. Com efeito, a história narra a inquirição relativa ao assassínio de um tio-trisavô do narrador na serra algarvia, no sul de Portugal, integrando aspectos da vida pessoal do narrador (iniciação política ao marxismo, a história da explicadora de francês...), tornando por vezes formalmente indistinguíveis as duas vidas e os dois tempos (séculos XIX e XX); reconhecendo em figuras actuais as antigas personagens (tio-trisavô e sua noiva de quinze anos), bem como operando uma aproximação ("mise en abyme") de atitude psicológica do trisavô, de Karl Marx e do próprio narrador após ter passado a barreira dos trinta anos.

Não por acaso, antes como elemento estrutural do horizonte temático das narrativas de Nuno Júdice, a exploração da vida de santos (Por Todos os Séculos) e a iniciação juvenil no marxismo (Plâncton e O Anjo da Tempestade) constituem, em 2009, duas das mais importantes vertentes da novela Os Passos da Cruz, título religiosamente emblemático resgatado pelo autor de uma anterior obra:

O sonho da Índia, desfeitas as ilusões d'Os Lusíadas com os passos da Cruz da Peregrinação de Fernão Mendes Pinto e da História Trágico-Marítima, não aparece na nossa literatura, nem sequer sob o manto diáfano de um exotismo que não faz parte da nossa cultura. ${ }^{5}$

${ }^{5}$ JÚDICE, 1997, p. 14. 
"Passos da Cruz" significa, assim, para o autor, a descida aos infernos da expiação histórica de um mal (passagem da visão heróica de Portugal em Camões para a visão anti-heróica descrita na Peregrinação de Mendes Pinto, bem como a emergência das catástrofes da História Trágico-Marítima), o que evidencia, como título da novela, que a visão degradante de Portugal oferecida pela corte de D. Afonso VI e pelo casamento interesseiro de Brás Teles com Antónia Margarida, na segunda metade do século XVII (após o momento heróico inicial da Restauração) se prolonga pelo Portugal do século XXI (sempre o paralelismo entre duas imagens que, em Nuno Júdice, desencadeiam o processo de mise en abyme - neste caso, a síntese da história de 800 anos de Portugal por via da narração de dois episódios temporalmente diferenciados por 300 anos). Neste sentido, não é Cristo o sujeito subentendido do título da novela ("Quem percorre os passos da Cruz?"), mas Portugal, tão violentado pela história após a época de ouro dos Descobrimentos como Jesus após a denúncia no horto das Oliveiras. Assim, Rosa (condensado estético e vivencial das personagens Rosa, Rita e Laura de Plâncton, de 1981) encontra-se para a iniciação universitária do narrador (sem nome) como a "Historiadora" para o seu cepticismo epistemológico e histórico de adulto; do mesmo modo, Antónia Margarida, fidalga do século XVII, está para o esposo Brás Teles de Meneses, que a violenta e humilha, como a sua homónima do século XXI para o marido de nome homónimo; assim como, ainda, Portugal da segunda metade do século XVII, país decadente, pobre por efeito de uma guerra de 30 anos contra Castela, de elites profundamente desorientadas (o ouro do Brasil é descoberto apenas em 1690, já no reinado de D. Pedro II), se encontra para o Portugal de hoje, país de elites decadentes, reinando soberanamente na cauda da Europa.

No mesmo texto, um rasgão no tempo cronológico, unindo dois períodos tão conjunturalmente diferentes quanto 
estruturalmente semelhantes, evidencia, imageticamente (ou literariamente) uma síntese condensada do todo da história de Portugal, bem como sustenta, estilisticamente, quase em filigrana, a manipulação preciosa da técnica de mise en abyme. Neste sentido, se a algum escritor português vivo, após a morte de Augusto Abelaira, se aplica correctamente a expressão de que, por mais múltiplos e diferentes romances que escreva, se encontra sempre a escrever o mesmo livro, utilizando a mesma técnica e insistindo na mesma temática, esse é, indubitavelmente, Nuno Júdice.

O Complexo de Sagitário (2011) confirma com prova maiúscula a utilização privilegiada da técnica de mise en abyme pelo autor. Confirma igualmente a hipótese de Nuno Júdice, como autor, se socorrer de uma visão culturalista da literatura. O culturalismo faz depender a observação da realidade exterior de uma inspiração cultural, isto é, de uma sabedoria literária, religiosa, científica experimentada e cumulada ao longo de uma vida de leituras. Neste sentido, culturalista é todo o escritor que, em concorrência com a observação da realidade social, se inspira em lendas clássicas, figuras mitológicas, símbolos civilizacionais, arquétipos culturais, tomando-os como centro ou enquadramento dos seus textos, apreendendo a realidade exterior, não por ela, consoante é vivida, mas por um olhar analítico enformado das grandes narrativas de uma civilização (a Bíblia, a mitologia greco-latina, os grandes textos medievais e renascentistas, as primeiras narrativas modernas...). Ou seja, a interpretação da realidade é feita através dos óculos graduados da cultura pelos quais a imagem cultural substitui a realidade, torna-se ela própria uma nova realidade - nasce assim a Arte e a Literatura. Assim as novelas de Nuno Júdice, nomeadamente Salomé, A Mulher Escarlate, Por Todos os Séculos, O Anjo da Tempestade e Os Passos da Cruz.

No caso de O Complexo de Sagitário, Nuno Júdice parte do cruzamento entre uma imagem extraída da leitura de A Filosofia 
na Alcova, de Sade, e a imagem mítica de Penélope tecedeira: "era Penélope que me obcecava", escreve o narrador. ${ }^{6}$ Assim, a vivência rural da cosedura dos enchidos do porco após a matança do animal pelas mulheres da aldeia, acompanhadas de três jovens urbanas em visita, Eugénia, Irene e Madalena, é associada pelo narrador ao acto delicado de bordar da Sra. de Saint-Ange, de Sade, e ao infindável acto de malícia por que Penélope ludibria os pretendentes aos seu leito e ao trono de Ítaca. Isto é, um episódio tradicional do ruralismo europeu é elevado, por via do alguidar de sangue e do manuseamento das agulhas, a arquétipo do destino do homem - o sangue como símbolo da expiação humana (o sacrifício, o penar por que se sofre a vida) e as agulhas como símbolo da tessitura labiríntica do destino, pequena parte em poder do homem, transcendendo-o a maior parte. Sobre estes dois arquétipos culturais, totalidades singulares da existência humana, o narrador peregrina em torno de outras referências culturais, de que enche o texto: Orfeu e Eurídice, Nietzsche, Lou Salomé e Paul Rée, Lady Macbeth e Shakespeare, Dante, Proust, Bataille, Botticelli, Pessoa e Ofélia, Nabokov, Prosérpina, Mérimée...

Como se constata, centrando o texto numa experiência específica (o acto de se coser as tripas do porco num alguidar cheio de sangue) e numa relação específica (a vivência do narrador com as três raparigas), o narrador mimetiza, labirinticamente, ao longo da totalidade de $O$ Complexo de Sagitário, o acto da criação literária como ponto de fuga para o infinito, acto transcendente (nunca completo nem perfeito) e transcendental (mas motor estético recorrentemente ambicionado em cada novo livro) que, como pólo invisível, se exprime no acto apelante do sacrifício (o sangue, símbolo da violência de uma busca nunca satisfeita) e no acto de recriação permanente do mundo através da

${ }^{6}$ JÚDICE, 2011, p. 12. 
tessitura sem solução de palavras em frases (Penélope e a metáfora da criação do mundo através da urdição do tecido e da manipulação das agulhas).

Neste sentido, O Complexo de Sagitário explicita, não argumentativamente, mas ficcionalmente, por via de sinais estéticos e símbolos civilizacionais, uma teoria da literatura. Esta, como pulsão do corpo, nasceria de um desequilíbrio (a violência do sacrifício do porco, as mulheres de braços sujos de sangue; o texto que se tece infinitamente sem esgotar a totalidade das possíveis combinações de palavras, como Penélope e os seus dias inúteis, impossibilitada de terminar definitivamente a obra), de uma busca nómada, uma peregrinação eterna, e dirigir-se-ia, como objectivo último, a um ponto obscuro (o "complexo de Sagitário"), um buraco negro, que, em vórtice, numa paradoxal espiral labiríntica, substituiria totalmente a realidade - o Ser - pela sua representação estética - o Símbolo. Este, sem suporte ontológico, anula a primeira realidade (o referente) e idolatra e entroniza a palavra (a imagem) com o nome de "história da literatura". Em fissura com a realidade, a Literatura compõe-se de múltiplas representações, um carnaval de representações estéticas (as correntes literárias, os autores, as influências, a intertextualidade), todas concorrendo entre si, umas anulando outras, umas superando outras. Por isso, em O Complexo de Sagitário sucedem-se as interpretações do acto fundador da novela e da renúncia do narrador ao acto de amor que Eugénia lhe oferece.

Deste modo, nesta novela, Nuno Júdice postula a literatura (1) como acto de criação anti-sistemático, anti-lógico, deslumbrado por uma verdade inatingível, vazia porque nunca definitivamente preenchida, a que os antigos chamavam "Beleza", um infinito de luz perturbante de que cada grande autor reflecte apenas alguns revérberos cintilantes; (2) como criação de um texto que arma o cerco ao "buraco negro" (o "Belo"), expresso por uma 
"angústia indefinida", 7 o sentimento de infinito pulsante no coração e na mente de todo o grande escritor, pelo qual se sente ferozmente sugado - experiência cristalizada na sabedoria dos antigos através do lema "abyssus abyssum invocat"; (3) como tentativa de perscrutar por palavras o mistério do mundo ou "a fonte da vida" (título de um livro de poesia do autor), de captar a energia sábia ilimitada disseminada em cada texto, tentativa que esteticamente esmaga todas as categorias literárias académicas (selva de conceitos abstractos que matam o sentimento estético - nada é mais inútil do que ler uma introdução aos estudos literários e nada mais útil que ler uma história da literatura); (4) como acto de criar que estabelece espontaneamente uma fissura entre realidade e escrita, tomando esta como patamar de acesso à decifração (eternamente gorada) de enigmas e mistérios que, revelados, logo de outro modo se disfarçam, empurrando forçosamente o escritor tanto para a captação intelectual das grandes verdades humanas, quanto para um silêncio cheio de lucidez.

No final, Literatura e Religião identificam-se na origem e diferenciam-se nos objectivos: o sentimento de infinitude é o mesmo, a que a religião chama Deus e o escritor o vazio (a "angústia") a pulsar no coração do homem, o indeterminado, $\mathrm{o}$ indefinido, o incerto, o ilimitado - justamente os nomes para Deus atribuídos pelos primeiros filósofos da nossa civilização. Os objectivos são diferentes: a religião transforma o vazio em plenitude, a literatura permanece com o vazio no peito, anda com ele ao colo desde que o homem narrou a primeira história na planície, à volta da fogueira. Ontologicamente, o balbuciar da primeira história não é muito diferente de um romance actual de 300 páginas. Eis o "complexo de Sagitário".

7 JÚDICE, 2011, p. 13. 


\section{Referências}

JÚDICE, Nuno. Plâncton: romance. Lisboa: Contexto, 1981.

JÚDICE, Nuno. O Tesouro da Rainha do Sabá: conto pós-moderno. Lisboa: Edições Rolim, 1984.

JÚDICE, Nuno. A Mulher Escarlate. Porto/Lisboa: Contexto/ Civilização, 1997.

JÚDICE, Nuno. Viagem por um Século da Literatura Portuguesa. Lisboa: Relógio d'Água, 1997 (1. ed., Paris: Escampette, 1993).

JÚDICE, Nuno. Por todos os Séculos. Lisboa: Quetzal, 1999.

JÚDICE, Nuno. O Anjo da Tempestade. Lisboa: D. Quixote, 2004.

JÚDICE, Nuno. Actualização Histórica. [Entrevista conduzida por Luís Ricardo Duarte]. Jornal de Letras, Artes e Ideias, Lisboa, 17 - 30 Junho 2009.

JÚDICE, Nuno. Os Passos da Cruz. Lisboa: D. Quixote, 2009.

JÚDICE, Nuno. O Complexo de Sagitário. Lisboa: Dom Quixote, 2011.

\section{Resumo}

Quase todas as narrativas de Nuno Júdice são subordinadas à dificílima técnica estilística de mise en abyme, num trabalho consciente com categorias tradicionais da narrativa tais como o tempo e o espaço, visando a exploração da dimensão meta-literária da ficção. No caso de Os Passos da Cruz (2009) este processo sofre um elevado grau de depuração, naquilo que se afigura como uma síntese do todo da história de Portugal. Já em O Complexo de Sagitário (2011) não só se confirma com prova maiúscula a utilização privilegiada da técnica pelo autor, como se torna patente a presença de uma visão culturalista da literatura enformando a sua produção novelística. 


\section{Resumé}

Presque tous les récits de Nuno Júdice sont subordonnés à la difficile technique stylistique de la mise en abyme, dans un travail conscient avec des catégories traditionnelles de la narrative tels que celle du temps et de l'espace et dans le but d'y exploiter la dimension métalittéraire de la fiction. Dans le cas de Os Passos da cruz (2009), ce processus subit une forte épuration, dans ce qu'il y a de synthèse de l'histoire du Portugal. Pour ce qui est de $\mathrm{O}$ complexo de Sagitário (2011), l'usage privilégié de cette technique s'affirme à nouveau, comme l'on peut le constater par la présence d'une vision culturaliste de la littérature, évidente dans sa production romanesque. 